\title{
A Study of Military Recruitment Strategies for Dentists: Possible Implications for Academia
}

\author{
Ronald H. Hsu, D.D.S., M.S.; Michael W. Roberts, D.D.S., M.Sc.D.; J.F. Camilla Tulloch, \\ B.D.S., F.D.S., D.Orth.; Carroll-Ann Trotman, B.D.S., M.A., M.S.
}

Abstract: Results of the annual American Dental Education Association surveys of dental school seniors show approximately 10 percent of graduates enter federal government services while less than 1 percent enter dental academia. To examine this difference, this study sought the perceptions of senior dental students and junior military dental officers regarding their choice of a military career in order to determine how military recruitment strategies influenced their career decisions. Official documents explaining military recruitment efforts were requested from the military services and summarized. In-depth telephone interviews were conducted to gather perception data from the students and dental officers on successful strategies. By employing several strategies, the military was able to inform potential recruits about the benefits of being a dentist in the military. The opportunity to have the military finance a student's dental education was a successful military recruitment tool. Other enticing factors included guaranteed employment upon graduation, prestige associated with serving in the military, access to postgraduate training, minimal practice management responsibilities, and opportunities to continue learning and improve clinical skills without significant financial implications. It was concluded that dental education can use the same strategies to highlight the benefits of an academic career and offer many similar incentives that may encourage students to consider a career path in dental education.

Dr. Hsu was a Resident in the Department of Pediatric Dentistry, University of North Carolina at Chapel Hill School of Dentistry at the time this research was conducted and is currently in private practice in Vancouver, WA; Dr. Roberts is Henson Distinguished Professor and Associate Chair, Department of Pediatric Dentistry, University of North Carolina at Chapel Hill School of Dentistry; Dr. Tulloch is Distinguished Professor and Chair, Department of Orthodontics, University of North Carolina at Chapel Hill School of Dentistry; and Dr. Trotman is Professor, Department of Orthodontics, and Assistant Dean for Graduate Education and Academic Development, University of North Carolina at Chapel Hill School of Dentistry. Direct correspondence and requests for reprints to Dr. Ronald H. Hsu, 8700 NE Vancouver Mall Dr., Suite 202A, Vancouver, WA 98662; 425-830-4920 phone; dr.ron. hsu@gmail.com.

This study is supported by grants from the American Association of Orthodontists Foundation and the Maternal and Child Health Grant \#2 T17 MC 00015-14-00

Key words: military dentistry, dental academia, recruitment

Submitted for publication 8/28/06; accepted 1/5/07

$\mathrm{T}$ The American Dental Education Association (ADEA) has been conducting annual surveys of senior dental students since the 1980 s to garner information on the students' experiences while at school and their subsequent career plans. The data returned has been consistent over twenty-five years: approximately 86 percent of seniors surveyed expressed intentions to enter private practice or pursue an advanced education program. Ten percent planned to enter federal government service, but less than 1 percent indicated that they would pursue a career in dental academia. ${ }^{1}$ The difference in the number of dental graduates choosing federal government service versus academia raises questions regarding recruitment strategies by the two entities.

The federal government services as defined by the ADEA surveys include Veterans Affairs, U.S. Public Health Service, National Health Service
Corps, U.S. Navy, U.S. Army, and U.S. Air Force. Although all federal services recruit dentists and dental students to join their programs, the military (Navy, Army, Air Force) is the focus of this article, given the availability of recruitment records. Students are introduced to the military services by attending recruiter presentations, having discussions with instructors or family dentists, ${ }^{2}$ viewing display booths at dental conventions, ${ }^{3}$ and reading advertisements in dental journals. ${ }^{4-9} \mathrm{~A}$ common belief is that financial incentives are the most successful recruitment tools used by the military; however, this has not been supported by salary data. Although scholarships reduced the financial burden of a dental education, the average base salary of a junior military dental officer in 2001 was less than one-fourth the average income of a private practicing general dentist ${ }^{10}$ and less than half the average income of a junior faculty 
member. ${ }^{11}$ However, there are other perceived benefits of a military career ${ }^{12}$ that include participation in major physical training and combat exercises, development of administration and leadership skills, enrollment in specialty training opportunities, refinement of clinical skills, opportunities for travel, and the experience of living in different cultures when stationed overseas. $^{13}$

Career decisions are often based on a number of factors such as educational debt, lifestyle, and ethnic background. ${ }^{1}$ Military recruitment activities may or may not have exerted additional influences on individual perceptions and circumstances. Thus, in addition to providing detailed descriptions of military recruitment activities and strategies, this study sought to identify dental students' perceptions of a career in the military services and examine the realities of military service as expressed by dental officers who had served in the military in the past five years. This study could potentially identify military recruitment strategies that may be applicable to academic dentistry.

\section{Methods}

\section{Identifying Military Strategies: Collection of Official Documentation}

Official documentation of recruitment activities was requested from the U.S. Navy, U.S. Army, and U.S. Air Force to identify various recruitment strategies used by the military and their effectiveness. The following information was requested from the three dental services: 1) the annual dentist recruitment goals of each service from 1997 to 2005, including the population pools targeted for recruitment and the number of dentists recruited since 1997 (a measure of success of the military in meeting their recruitment needs was determined by examining the number of vacant positions versus the number of recruits attained); and 2) a description of all recruitment activities, including incentive packages offered to potential recruits.

\section{Perceptions of Potential Recruits: In-Depth Interviews by Telephone}

In-depth interviews (IDI) by telephone were used to identify and gather qualitative data about factors considered important by interviewees when making the decision to join the military. ${ }^{14}$ The interviewees were taken from the following two groups with specific inclusion criteria: 1) senior dental students selected from public, private, and private state-related schools of dentistry who had committed to enter military practice upon graduation; and 2) junior dental officers in the U.S. Navy, U.S. Army, and U.S. Air Force who had completed more than two, but less than five, years of his or her first assignment. The interviewer was a social scientist/psychologist with expertise in qualitative research and experiences in both academic and corporate research settings. The IDI questions were designed to elicit open-ended responses. The telephone interviews lasted approximately thirty to forty minutes.

Emails soliciting consent to participate were sent to administrators of the fifty-six American Dental Association (ADA)-accredited dental schools in the United States. The administrators were asked to forward the letters to all senior students who met the inclusion criteria. Interested students were instructed to contact the principal investigator (PI) via email and give consent to participate in the study. No two participants from the same school were interviewed to ensure that no school was oversampled. Lists of junior dental officers in the three military services who met the inclusion criteria were requested from the dental corps. The qualifying officers were contacted by email. The first two officers from each service who agreed to participate were consented via email and enrolled into the study. Each interview began with a brief introduction describing the study.

The interview questions were the same for students and officers. They probed the following areas: initial awareness of military opportunities and the specific source from which this information was obtained; primary reasons for joining the military; and views on a hypothetical scholarship program for academic dentistry, modeled after the Health Professions Scholarship Program offered by the military (described later).

All interviews were tape-recorded. Data collection was considered complete when the interviewer, based on her notes and expertise in qualitative research methods, determined that little new relevant information was being provided by the participants. The tapes were coded for later transcription and review by the PI. This study was reviewed and approved by the Institutional Review Board of the University of North Carolina at Chapel Hill School of Dentistry. 


\section{Results}

\section{Official Documentation from the Military}

The Navy Recruiting Command returned a complete report of the requested information accompanied by detailed statistics, but the Army and Air Force provided only partial information. The Army returned results for years 2001-05, and the Air Force returned cursory data for 2003-04. Both services were unresponsive to follow-up requests. The reports submitted by the military branches demonstrated similar recruitment methods and incentive packages.

Recruitment Strategies. The most commonly employed recruitment strategies were twice-yearly visits to dental schools and having information booths at dental conferences. Occasionally, the Navy would select outstanding junior dental officers and assign them to "reverse VIP trips." These trips, which involved special lunch and learn sessions for dental students at the schools from which the officers graduated, were designed to take advantage of the junior officers' familiarity with the school and students. Other strategies included print and multimedia advertisements such as CDs and DVDs mailed directly to potential recruits. These mailings also directed recipients to Internet websites. Other mass media efforts including radio and television advertisements were used to reach the public. Potential dental officers were recruited from university undergraduate students, dental students, specialty residents, general dentists in private practice, specialty dentists, and dentists and specialists who were in the active and inactive reserves of the military services. Table 1 illustrates the military recruitment strategies and the targeted population pools.

The military used two additional recruitment strategies for those students and dentists who identified themselves as being interested in a military career. Face-to-face meetings were held with these potential recruits at which time the recruiter explained the benefits of being a military dental officer, the military lifestyle, and training opportunities. The student or the dentist was encouraged to ask questions, and the recruiter addressed possible concerns. VIP trips for spouses and family members were designed to showcase the dental clinics, military bases, surrounding communities, and housing quarters to familiarize the recruits and their families with the military lifestyle.
Standard Military Compensation. The standard compensation packages provided to dental officers of all three military branches are identical, although small variations may arise depending on type and location of duty assignments. In summary, the military services offer an annual salary that is a combination of base salary, housing allowance, subsistence allowance, and professional pay. The amount of pay an officer receives is based on rank, years of service, assignment location, and whether the officer is boardcertified by one of the ADA-recognized specialties. All officers receive thirty days of paid annual leave and federal holidays. Comprehensive health care benefits are provided at no cost to the officers, and their family members receive similar services at a low cost. Attendance at approved continuing dental education courses is supported. Officers also may have the opportunity to pursue supported postgraduate or specialty training while continuing to receive full pay and allowances while in training. Dental officers have malpractice insurance provided by the military. Opportunities for both business and leisure travel aboard military aircraft are available.

Promotional Incentives. In addition to the standard compensation packages, other incentives are promoted by recruiters. A dentist receives a $\$ 30,000$ signing bonus upon joining the service, and dental students who qualify for a Health Professions Scholarship Program (HPSP) receive scholarships that fund their dental education for two to four years (depending on the terms of service contracts). These scholarships cover fees, tuition, books, instruments, and equipment and provide a monthly living allow-

\footnotetext{
Table 1. Military recruitment efforts

Recruitment Strategies Employed

- Internet websites specifically designed for recruitment

- Dental school lunch and learn sessions

- Direct mailing of print and multimedia material

- TV/radio advertisement

- Information booth at ADA and other dental meetings

- Face-to-face meetings and "VIP" visits for family members and significant others

Recruitment Target Groups

- University predental students

- Dental students and specialty residents

- General dentists and dental specialists in private practice

- Dentists in military reserves

- Former military dentists
} 
Table 2. Recruitment incentives emphasized to target groups by the military services

- Financial support for dental education

- Signing bonus $(\$ 30,000)$

- Comprehensive health care for dentist and dependents

- Financial support for continuing education activities

- Specialty training opportunities with financial support

- Domestic and foreign duty assignments with travel support

- Any U.S. state or territorial dental license is acceptable (mobility)

- No business pressures such as those associated with private practice

interviewed between November 2004 and April 2005. The PI of this study reviewed the transcribed and coded interviews to identify major themes within each of the specific areas that were explored.

Initial Awareness of Military Opportunities and From What Source. Awareness of military dental career opportunities prior to or during the first year in dental school was widespread. Students may have had previous affiliations with the military either personally or indirectly through a

ance. Postgraduate specialty students are eligible for a financial assistance program that covers tuition and fees for the training program and provides a stipend.

Besides the HPSP, two other programs are available to dental students. The first simply guarantees the student a job upon graduation and a $\$ 30,000$ signing bonus. The second program, the Health Services Collegiate Program, enrolls dental students into the military as enlisted personnel. This status entitles students to the benefits of being in the military and allows them to accrue active-duty credit, which can increase their salary after they graduate and become dental officers. The military also recruits dentists into the reserves with various compensation packages. Table 2 shows the incentives offered and emphasized by military recruiters.

Recruitment Statistics. The recruitment data provided by the Navy, Army, and Air Force are presented in Tables 3-5. Annual goals and attainments for the different recruitment programs are listed. As stated previously, the Army and the Air Force returned incomplete datasets, but it is apparent that they use fewer incentive recruitment programs than the Navy. Separate information was provided for before and after the World Trade Center disaster in New York that occurred on September 11, 2001, to highlight the impact of war on military recruitment effectiveness. Based on data returned, the recruitment success of the HPSP for all three military services was minimally reduced subsequent to $9 / 11$, but other incentive programs became less appealing to candidates.

\section{In-Depth Interviews}

The individuals interviewed for this aspect of the study comprised ten dental students and six military officers (Figure 1). All of the student interviews were conducted between November 2004 and February 2005, and the military officers were family member. Additional information came from presentation sessions and classmates who have been recipients of military scholarships or from professors and/or family dentists who have had military experiences. Predental clubs and academic advisors were another source of information, and military presentations were frequently included as part of new student orientation. Television/radio advertisements and information booths at dental conferences were not mentioned as being the initial source of awareness regarding military service opportunities.

Here is a sample response from a dental student: "I come from a military family you know, [and] the option was presented to me. . . . I went to each branch and I know individuals in each branch and I just wanted to see what each would entail. ... [Then] during orientation there were all kinds of presentations on financial aid, and what to do in [the city where the school is], where to live, etc., and part of that program is they have the military come in and speak. Then there were the lunch and learns."

Here is a sample response from a military dental officer: "I was accepted to dental school and then started thinking about how I was going to pay for it. I talked with the predent/premed advisor at our school, and he gave me one number for the Army and I called them up, and then I hooked up with the Air Force and Navy recruiters. Then there was the free lunch with a pretty good recruiter."

Primary Reasons Given for Joining the Military. Alleviation of indebtedness was clearly a major reason for joining the military. Other reasons that influenced career considerations and were frequently cited included the following: the military option provided a sense of security by guaranteeing employment immediately upon graduation and giving full health care benefits along with disability and malpractice insurance; serving in the military satisfied patriotic sentiments and provided the dentists with a certain amount of prestige that was perceived as 


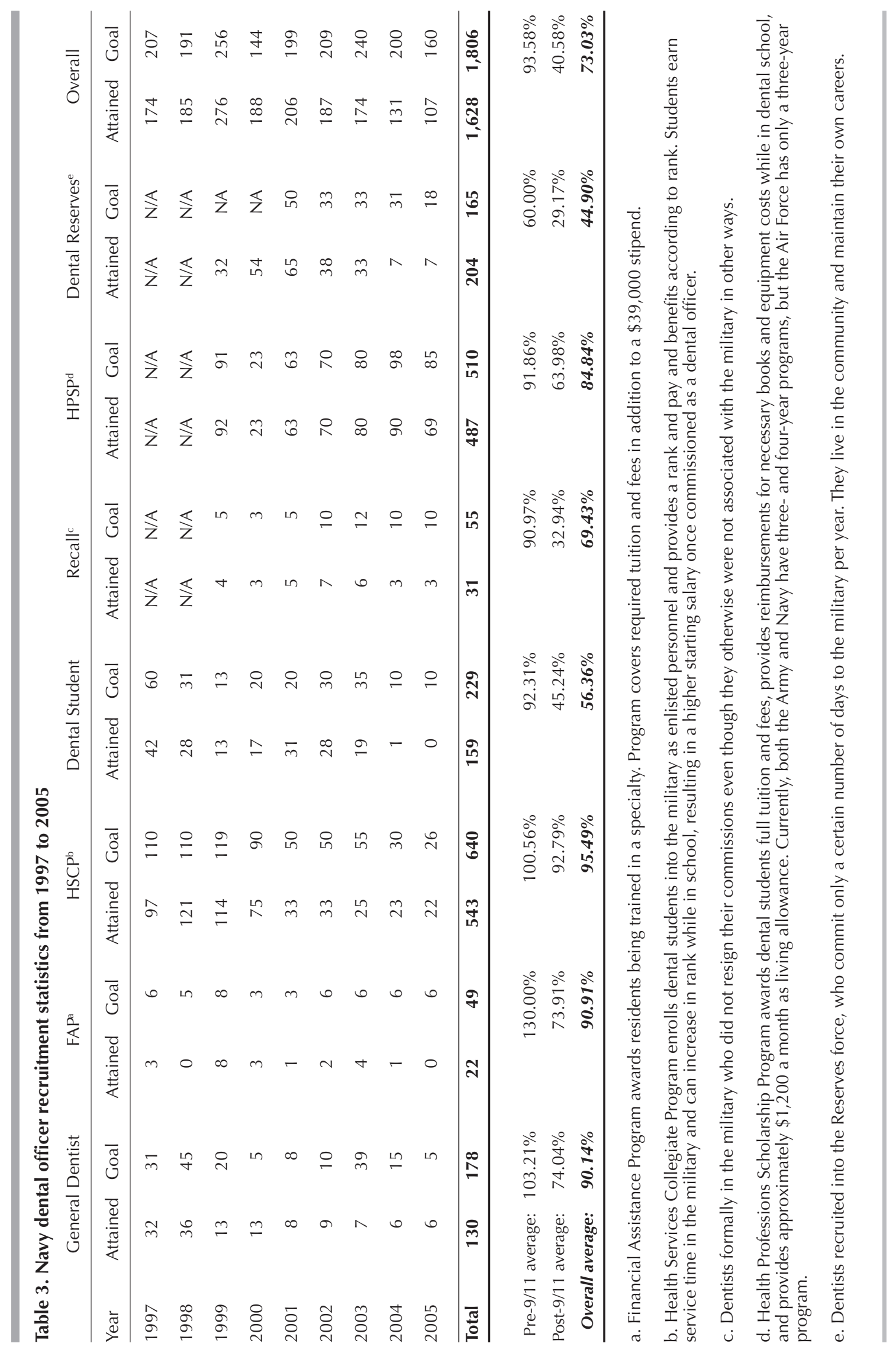


Table 4. Army dental officer recruitment statistics from 2001 to 2005

\begin{tabular}{|c|c|c|c|c|c|c|c|c|c|c|}
\hline \multirow[b]{2}{*}{ Year } & \multicolumn{2}{|c|}{ General Dentist } & \multicolumn{2}{|c|}{ Specialty Dentist } & \multicolumn{2}{|c|}{ HPSP } & \multicolumn{2}{|c|}{ Dental Reserves } & \multicolumn{2}{|c|}{ Overall } \\
\hline & Attained & Goal & Attained & Goal & Attained & Goal & Attained & Goal & Attained & Goal \\
\hline 2001 & 15 & 20 & 5 & 18 & 88 & 87 & 115 & 100 & 223 & 225 \\
\hline 2002 & 11 & 20 & 3 & 18 & 94 & 93 & 94 & 100 & 202 & 231 \\
\hline 2003 & 16 & 25 & 3 & 10 & 99 & 97 & 30 & 35 & 148 & 167 \\
\hline 2004 & 9 & 30 & 1 & 10 & 119 & 118 & 18 & 35 & 147 & 193 \\
\hline 2005 & 16 & 30 & 2 & 12 & 83 & 93 & 11 & 36 & 112 & 171 \\
\hline Total & 67 & 125 & 14 & 68 & 483 & 488 & 268 & 306 & 832 & 987 \\
\hline \multicolumn{2}{|c|}{ Pre-9/11 average: } & $75.00 \%$ & & $27.78 \%$ & & $101.15 \%$ & & $115.00 \%$ & & $99.11 \%$ \\
\hline \multicolumn{2}{|c|}{ Post-9/11 average: } & $49.52 \%$ & & $18.00 \%$ & & $98.50 \%$ & & $74.27 \%$ & & $79.92 \%$ \\
\hline \multicolumn{2}{|c|}{ Overall average: } & $53.60 \%$ & & $20.59 \%$ & & $98.98 \%$ & & $87.58 \%$ & & $84.30 \%$ \\
\hline
\end{tabular}

Table 5. Air Force dental officer recruitment statistics for 2003 and 2004

\begin{tabular}{lcccccc} 
& \multicolumn{2}{c}{ Dentists } & \multicolumn{2}{c}{ HPSP } & \multicolumn{2}{c}{ Overall } \\
\hline Year & Attained & Goal & Attained & Goal & Attained & Goal \\
\hline 2003 & 10 & NA & 31 & NA & 41 & 101 \\
2004 & 32 & NA & 69 & NA & 101 & 94 \\
Total & 42 & NA & 100 & NA & 142 & 195 \\
Pre-9/11 average: & NA & & NA & & NA \\
Post-9/11 average: & NA & & NA & & $72.82 \%$ \\
Overall average: & NA & & NA & & $72.82 \%$ \\
& & & & & &
\end{tabular}

attractive to future employers or patients; the military provided postgraduate residency opportunities in both general practice and specialty training; the opportunity to practice dentistry in a protected environment was appealing and permitted new graduates to sharpen their clinical skills without practice management concerns such as malpractice insurance, production, collection, and staffing; and the opportunity in practice to take as much time as needed to perform clinical procedures as well as to learn from more experienced dentists was also appealing. Other motivators for joining the military included having opportunities for domestic and international travel and assignments and having the flexibility and convenience of short-term employment when the individual is not ready to make long-term commitments. Interestingly, the $\$ 30,000$ sign-on bonus was not listed as a motivator.

Here is a sample response from a dental student: "Financial was the primary reason for me to investigate this [military opportunity] but I would have been interested even if there had not been those incentives. When I have lunch with my friends in dental school, they all kind of expressed to me that they wished they would have looked into something like this [because] first of all it is a job opportunity. Upon graduating dental school, even though you may have your degree, you are not guaranteed work. You have to go out there and sell yourself; find an office if you are not starting up your own practice. The Air Force has it all ready to go. They provide the assistants for you, the patients, the instruments . . . everything is ready to go, so that is definitely an attractive option immediately graduating from dental school. The second thing is I think it is pretty prestigious to say that you are a part of the Air Force. I am going to be a captain [and] I think that is pretty important to have on my resume. ... And you are doing this for your country. The Air Force is a big team. It is a cohesive unit that is going to make those first couple of years out of dental school easier for me-a learning experience where I get to learn from more experienced officers and fine-tune my trade."

Here is a sample response from a military dental officer: "While I was in dental school, I thought about how much money I was going to owe, so right after my first year I started looking into [military opportunities]. So it was the money and the fact that I really didn't know exactly what I wanted to do after I got out of dental school. I thought I could join for three years and delay that decision for a little while. I thought maybe I could travel a little bit. And they seemed to have a good opportunity for advanced education. I [ended up] doing an AEGD [in the Air Force]. I guess I [felt that] I would gain a lot of clini- 

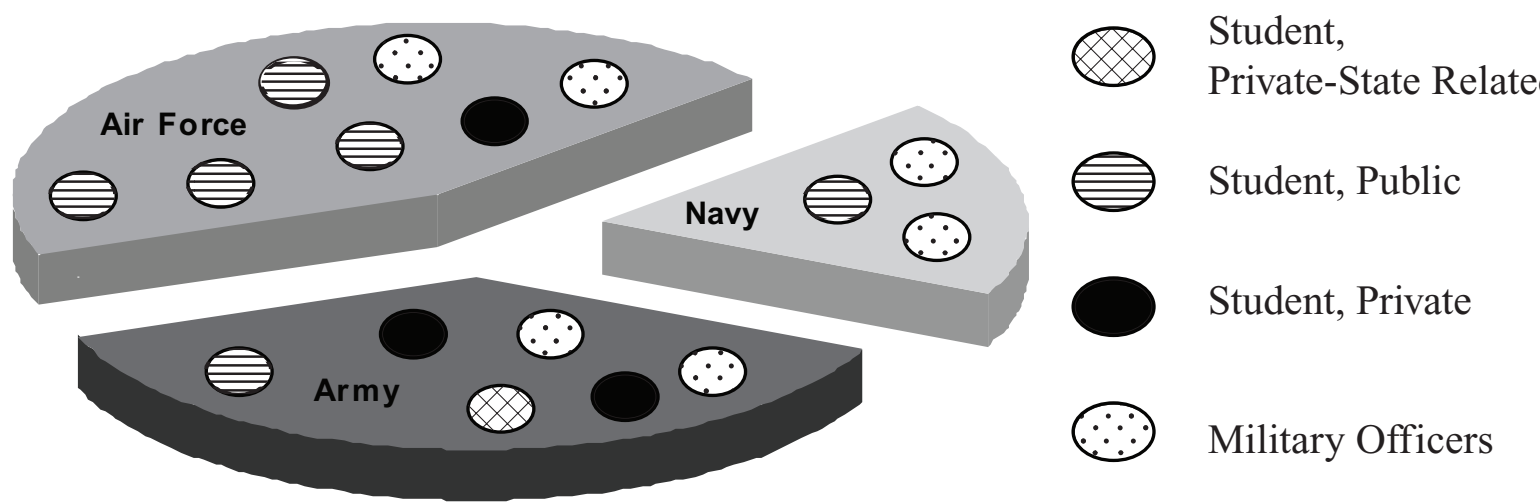

Figure 1. Composition of study sample $(n=16)$

cal experience versus jumping right into a private practice from dental school. . . . A lot of times you aren't sure of your skills and you feel very inept as a dentist at that point, so I knew that in the Air Force you are still surrounded by a lot of good people who can help you and people who can answer questions for you - a much more protected environment."

Views on a Hypothetical Scholarship Program. Reactions were mixed when a hypothetical scholarship program for academic dentistry was presented to the participants. They showed interest in the described program as another opportunity for debt relief, but voiced reservations. The teaching aspect of an academic career was attractive, but the research component was less so. Interviewees thought that such a program would be of interest to some of their classmates who exhibited an aptitude to teach, conduct research, or were interested in administration, but would be less attractive to those interested in entering private practice at a later date. The perception was that academia, with its teaching, research, and service responsibilities, would detract from clinical practice opportunities. Participants suggested that a residency program or some additional training program be part of the scholarship to address a perceived deficit in clinical experience. Allowing scholarship recipients at least two days per week for private practice would make the program more appealing.
Sentiments were expressed that it would be important, if such a scholarship program was implemented, that the scholarship recipient not be required to remain at the same school at which their dental training occurred. There was concern expressed that if the scholarship recipient was required to remain as faculty at the same dental school where they graduated, he or she would not be treated as an equal by some senior faculty members. Particularly worrisome was the potential that faculty administrators would simply assign the least appealing tasks to the new graduate/faculty member. The opportunity to gain a different perspective by going to another dental school to fulfill their teaching commitment was mentioned as attractive and would increase the appeal of the hypothetical scholarship program.

Here is a sample response from a dental student: "I think [the hypothetical scholarship program for academia] would be appealing. I think people would jump on it because for those who are unsure of what they want to do, it would be a nice avenue to teach. It will increase the amount of educators, but I don't think it will help the students; I just don't think students directly coming out of dental school have any experience at all to teach. So if they provided additional training like a residency, it would be very attractive. That type of experience would also be very important for somebody who may want to leave after their commitment and go into private 
practice. If I thought I wasn't going to come out as a significantly better clinician, then it would be unattractive. Also, I don't know if I would have wanted to stay at the same school. Some instructors make our lives pretty miserable, especially the first two years, and the idea of spending another three years here would have killed the deal for me. I want to do something else. I think that going to another school and getting another perspective on dentistry would be appealing to me. So having the flexibility of being able to choose the university you want to be at would be important."

Here is a sample response from a military dental officer: "I probably would have checked into [the hypothetical scholarship program for academia] but I don't know. I am not big into research; I wanted to do dentistry so [I would] probably not [pursue it]. ... If they tell you they are going to pay for your dental school, of course you are going to hear them out, but I would have chosen the military over it in a second. I definitely could see this program being very appealing to other students though, but not everybody is cut out for it. I can think of many people I would hope never ever would teach in a school."

\section{Discussion}

It is apparent that those who committed to the military service were familiar with the military through a variety of means. Personal experiences in the military and conversations with family, friends, faculty, and dentists who had military experiences provided motivation to investigate military dental careers. Proactive recruitment activities by the military were also useful in providing prospective dental recruits with information regarding the military dental programs. Recruiter attitude and enthusiasm were influential. The interviewees saw the military primarily as a way to escape educational indebtedness; however, active duty service was also valued as an opportunity to continue learning and improving clinical skills. The military provided leadership training and managerial opportunities that were viewed by respondents as important skills helpful to the dentist in future private practice. Familiarity with the military lifestyle made the culture more acceptable, and the idea of being part of a team of dentists who interact with and learn from each other was highly valued. In summary, the interviewees appeared knowledgeable and well informed about military dental careers.
In contrast, information regarding an academic career seemed to be lacking and may partly be to blame for the low interest among dental students. A recent study showed that dental students were woefully uninformed about careers in dental education, even though school administrators indicated that there were programs in place to familiarize them with academia. ${ }^{15}$ The same study also showed that students who have a higher self-reported knowledge of career options in dental education were more likely to pursue a part-time faculty appointment and have a more positive attitude toward entering full-time academics.

The implications are that military recruitment methodologies, if adapted by academic administrators and used effectively, could advance the knowledge level among dental students of academic careers and possibly increase the likelihood of individuals who were inclined towards an academic career to actually pursue such a career. Many aspects of the military program that were cited as attractive also exist in dental education. As in the military, dental faculty can avoid traditional business complexities. Dental institutions also traditionally provide health care, disability, and malpractice coverage. Colleagues with specialties are accessible and offer opportunities to gain additional expertise. Faculty are supported and encouraged to attend academic conferences and continuing education courses.

Leaders in dental education should consider establishing a national recruiting agency, similar to the Recruiting Commands of the military, which would oversee the recruitment efforts for all dental schools. ADEA has taken a lead in the establishment of the Academic Dental Careers Network, but more needs to be done beyond setting up a depository for individual curriculum vitae and institutional position announcements in cyberspace. A proactive approach spearheaded by dental education institutions and foundations, research organizations, and specialty organizations is needed. Detailed and focused discussions on issues of faculty recruitment and retention should be regularly addressed at local, regional, and national dental society meetings. These presentations could provide an update of the current faculty workforce opportunities and highlight the merits of an academic career.

Since 2001, articles publicizing dental academic workforce shortages and corrective efforts have appeared regularly. The awareness raised by these articles may have been part of the reason that, over the past three years, more than 50 percent of new 
faculty hires have come from private practitioners. ${ }^{16}$ To encourage and support that trend, the Academy for Academic Leadership, a private organization geared toward, among other things, helping private practice dentists who wish to transition to dental academia, was established. ${ }^{17}$ Most recently, the ADA launched an initiative called "Dental Education: Our Legacy, Our Future" to raise awareness and promote philanthropic efforts. ${ }^{18}$ At the time of publication, seventy-nine organizations had joined the campaign, including many dental schools. The academic community should continue to collaborate with other dental organizations to cultivate the private practice sector that is rich in clinical expertise and may be willing to contribute as faculty.

As stated by one of the dental officers interviewed, "If they tell you they are going to pay for your dental school, of course you are going to hear them out." Stakeholders in dental education must explore opportunities and be creative in implementing financial incentives such as debt relief in order to make academic careers more attractive to dental students and specialty residents. ADEA senior surveys have shown a rise in student indebtedness, and the associated financial pressures influence students' career plans immediately following graduation. ${ }^{1}$ If a scholarship program similar to the HPSP were offered for joining academic dentistry, that portion of the student population with an aptitude and inclination towards academia may choose to pursue such a career. The "Dental Education: Our Legacy, Our Future" campaign has a goal of raising $\$ 500$ million for dental education through December 31, 2014. It is conceivable that the ADA could lead a cooperative effort with federal and state agencies, dental schools, and the dental product industry to design a scholarship program that would give prospective educators the financial support and additional training they would need to succeed in dental academia.

The importance of interpersonal relations cannot be overlooked. Many students and officers interviewed were encouraged by family, friends, dental school faculty, and their personal dentists to explore military opportunities. Academicians must share with students, residents, and the dental community at large their enthusiasm for teaching, research, and service. The challenges and rewards of being an academician need to be conveyed. In addition, current faculty could help guide qualified individuals to opportunities that would prepare them for a career in academia. Unfortunately, our study confirmed the results of an earlier work where dental students perceived academic environments to be cold and negative. ${ }^{19}$ This must be changed. Teachers must remember that they are in a position to leave positive impressions on budding dentists and potential faculty. A seed, well planted and carefully cultivated, may blossom into the next expert instructor, brilliant researcher, or skillful administrator. It is imperative that students with an inclination for academia be identified early, supported, and encouraged.

\section{Conclusion}

The recruitment methodologies used by the military dental services have achieved consistently positive results. Although current armed conflicts have reduced the effectiveness of some recruitment efforts, scholarship programs continue to show success. Effective recruitment methods include personal experiences and information sessions. Attractive incentives include scholarships that eliminate or reduce indebtedness, offer employment security, provide benefits upon graduation, satisfy patriotic sentiments, extend postgraduate training opportunities, permit the practice of dentistry in a protected environment, and provide the opportunity to continue learning from more senior dentists. Examination, modification, and adaptation of similar recruitment methodologies used successfully by the military would appear to have merit for academic purposes. These findings support the development of a carefully crafted scholarship program and a central recruitment agency for academic dentistry. Dental schools in cooperation with federal and state agencies, private industry, and organized dentistry need to assist students in considering academic careers.

\section{REFERENCES}

1. Chmar JE, Weaver RG, Valachovic RW. Annual ADEA survey of dental school seniors: 2005 graduating class. J Dent Educ 2006;70:315-39.

2. Russell R. You can call her "Doctor" or you can call her "Captain" (Captain Carolyn L. Shreve). Dent Stud 1979;58:41.

3. Jochen DG. Forward march! Dent Econ 1981;71:98101.

4. Nathan RA. A dental career in the federal government. N Y State Dent J 1979;45:544,546.

5. Miller AG. Career pathways in dentistry. Dent Update 1999;26:82-3.

6. Castillo D, Lazarus M. Unlocking your career vision. Dentistry 1997; 17:4-6,8. 
7. Murray GH, Hancock AF, Fancher J, Chamberlain TM. The Air Force Dental Service: cross into the blue. J Am Coll Dent 2003;70:4-7.

8. Webb JG, von Gonten AS, Luciano WJ. Providing care for America's Army. J Am Coll Dent 2003;70:8-11.

9. Woofter DD, Peters A, Kvaska G, Turner CI, Peters RJ, Shaffer RG, et al. Navy Dental Corps: ninety years . . . and forward. J Am Coll Dent 2003;70:12-5.

10. Basic pay, effective July 1, 2001. At: http://armedforcescareers.com/payjul01.pdf. Accessed: November 13, 2006.

11. Faculty salary survey summary report: guaranteed annual salary, 2002-03; total compensation, 2001-02. Washington, DC: American Dental Education Association, 2004.

12. Greenwald J. It's not just a job: the adventure of military dentistry. Dentistry 1990;10:18-20.
13. Robinson BE. Postgraduate educational opportunities in the military services. J Am Coll Dent 2000;67:19-20.

14. Greenbaum TL. The handbook for focus group research. Rev. \& exp. ed. San Francisco: Jossey-Bass, 1993.

15. Rupp JK, Jones DL, Seale NS. Dental students' knowledge about careers in academic dentistry. J Dent Educ 2006;70:1051-60.

16. Chmar JE, Weaver RG, Valachovic RW. Dental school vacant budgeted faculty positions: academic year 2004-05. J Dent Educ 2006;70:188-98.

17. ADA News 2006;37(5):18.

18. ADA News 2006;37(13):1,8-9,12.

19. Trotman CA, Bennett E, Scheffler N, Tulloch JC. Faculty recruitment, retention, and success in dental academia. Am J Orthod Dentofacial Orthop 2002;122:2-8. 